\title{
Planned Activity Planned Duration
}

National Cancer Institute

\section{Source}

National Cancer Institute. Planned Activity Planned Duration. NCI Thesaurus. Code C93998.

The intended period of time for the planned activity as defined by the study. 